\title{
Tecnologias Digitais no Enriquecimento Extracurricular de Alunos com Altas Habilidades/Superdotação
}

Digital Technologies in the Extracurricular Enrichment of Students with High Skills/Gifted Students

Tecnologías Digitales en el Enriquecimiento Extracurricular de Estudiantes con Altas Habilidades/Superdotácion

\section{CLEONICE DA LUZ DOS SANTOS ${ }^{1}$, CLODIS BOSCARIOLI ${ }^{2}$}

${ }^{1}$ Universidade Estadual do Oeste do Paraná

${ }^{2}$ Universidade Estadual do Oeste do Paraná

RESUMO: Alunos com Altas Habilidades/Superdotação são público-alvo da Educação Especial, sendo
garantido o Atendimento Educacional Especializado como forma de enriquecimento extracurricular. Este
artigo tem por objetivo elencar Tecnologias Digitais que possam desenvolver as múltiplas inteligencias e
potencializar as habilidades destacadas à luz de um levantamento bibliográfico e documental, tendo como
base documentos legais, artigos e livros. Diante da análise, concluiu-se que a integração das Tecnologias
Digitais no ensino para Altas Habilidades/Superdotaşão vem ao encontro do anseio por atividades
significativas e desafiadoras, pois fortalecem a aprendizagem, enriquecem os curriculos extracurriculares e
proporcionam ao aluno o papel de pesquisador, ampliando seus conhecimentos e potencializando suas
babilidades de forma dinâmica e interativa. ALTAS HABILIDADES. SUPERDOTAÇÃO. TECNOLOGIAS DIGITAIS. ATENDIMENTO EDUCACIONAL ESPECIALIZADO. INTELIGENCIAS MÚLTIPLAS.

\footnotetext{
ABSTRACT High Ability/Gifted Students are the target audience of Special Education, with Specialized Educational Service being guaranteed as a form of extracurricular enrichment. This paper aims to list Digital Technologies that can develop multiple intelligences and enhance the skills highlighted in the light of a bibliographic and documentary survey, based on legal documents, articles and books. In view of the analysis, it was concluded that the integration of Digital Technologies in teaching for High Skills/Giftedness meets the desire for meaningful and challenging activities, as they strengthen learning, enrich extracurricular and provide the student with the role of researcher, expanding their knowledge and enhancing their skills in a dynamic and interactive way.

HIGH SKILLS. GIFTEDNESS. DIGITAL TECHNOLOGIES. SPECIALIZED EDUCATIONAL SERVICE. MULTIPLE INTELLIGENCES.
}

Os autores cedem à Revista Internacional Educon os direitos de primeira publicação do presente artigo. Aplicam-se os termos de uma licença Creative Commons Atribuição 4.0 Internacional (CC BY 4.0), que permite o uso irrestrito, a distribuição e a reprodução em qualquer meio desde que a publicação original seja corretamente citada. 
RESUMEN: Los estudiantes de Alta Capacidad/Superdotación son el público objetivo de la educación especial, con el servicio educativo especializado garantizado como una forma de enriquecimiento extracurricular. Este artículo tiene como objetivo enumerar las tecnologías digitales que pueden desarrollar inteligencias múltiples y potenciar las habilidades destacadas a la luz de una encuesta bibliográfica y documental, basada en documentos legales, articulos y libros. A la vista del análisis, se concluyó que la integración de las Tecnologias Digitales en la enseñanza de Altas Habilidades/Superdotación responde al deseo de actividades significativas y desafiantes, ya que fortalecen el aprendizaje, enriquecen los currículos extracurriculares y otorgan al estudiante el rol de investigador, ampliando sus conocimientos y potenciando sus habilidades de forma dinámica e interactiva.

HABILIDADES ALTAS/SUPERDOTACIÓN. TECNOLOGÍAS DIGITALES. SERVICIO EDUCATIVO ESPECIALIZADO. INTELIGENCIAS MULTIPLES.

\section{Introdução}

A Política Nacional de Educação Especial, na Perspectiva da Educação Inclusiva (2008) e outros documentos legais empregam o termo Altas Habilidades/Superdotação (AH/SD), concebendo como definição, potencial elevado em áreas como a intelectual, acadêmica, liderança, psicomotricidade e artes; podendo apresentar elevada criatividade. Os alunos com AH/SD dispõem de direito ao Atendimento Educacional Especializado (AEE) que objetiva a complementação e a suplementação de conteúdo, favorecendo seu desenvolvimento global.

No que tange às Altas Habilidades/Superdotação (AH/SD), consta no Manual de Orientação: Programa de Implantação de Sala de Recursos Multifuncionais (Brasil, 2010), que o AEE orienta e possibilita que alunos com $\mathrm{AH} / \mathrm{SD}$ sejam atendidos em suas especificidades com práticas pedagógicas direcionadas conforme a necessidade, sem molde pré-definido, exigindo do professor um planejamento flexível, com proposta de intervenção pedagógica que oportunize um ambiente desafiador, em um processo dinâmico de valorização da iniciativa e respostas não padronizadas dos alunos.

As Salas de Recursos para Altas Habilidades/Superdotação são importantes na identificação, acompanhamento e avaliação das necessidades educacionais do aluno, pois nelas são disponibilizadas atividades diversificadas com o objetivo de sanar as dificuldades e/ou a potencialização das habilidades apresentadas, visando ao desenvolvimento global e à autonomia, dentro e fora da escola, em consonância com a proposta do ensino comum, pois os sistemas de ensino devem proporcionar acesso aos espaços, recursos pedagógicos e à promoção da aprendizagem, bem como a valorização das diferenças e o atendimento das necessidades de todos os estudantes (Brasil, 2010). Desta forma, para que o aluno com AH/SD seja assistido em sua singularidade, faz-se necessário o reconhecimento de suas potencialidades. Freitas (2012) afirma que o aluno, por não ser identificado e estimulado, pode estagnar em seu desenvolvimento potencial, tornando-se frustrado e desinteressado.

As práticas pedagógicas devem promover ambientes de aprendizagem integrados para a promoção do conhecimento nas diferentes áreas de interesse, para além dos conteúdos programáticos estabelecidos em cada nível ou etapa de ensino. Para o enriquecimento extracurricular, as tecnologias digitais vêm ao encontro desta perspectiva de inclusão e dinamização do ensino das $\mathrm{AH} / \mathrm{SD}$, visto que vivenciamos uma evolução tecnológica significativa que possibilita a utilização de plataformas digitais, oportunizando diferentes alternativas à assimilação e elaboração de novos conhecimentos, bem como beneficiando o processo de aprendizagem colaborativa e enriquecendo o processo educacional.

Este artigo discute possibilidades de enriquecimento extracurricular de alunos com AH/SD com Tecnologias Digitais (TD). O estudo ora descrito é resultante de um estudo maior (Santos, 2019), que se objetivou a elaboração de uma proposta educacional do uso de tecnologias digitais, considerando as diferentes inteligências, no qual optamos por explorar recursos digitais que propiciam condições de 
inovação nas estratégias de ensino, mobilizando o interesse em aprender e progresso do potencial criativo de cada do aluno.

\section{Altas Habilidades/Superdotação: definições e indicadores}

Teóricos da linha da psicometria, área da psicologia que estuda a mensuração da inteligência, associavam a superdotação ao Quociente de Inteligência (QI) elevado, acima de 130, resultado da mensuração de testes psicológicos. De tal forma, consideravam o termo superdotado para "crianças com escore de QI muito altos, criatividade fora do comum ou talentos específicos excepcionais" (Boyd \& Bee, 2011).

Renzulli (1988) e Gardner (1995) redimensionaram os estudos sobre a temática, levando à discussão os testes padronizados de inteligência em áreas reduzidas como raciocínio lógico e linguística, valorizando somente as habilidades acadêmicas, excluindo habilidades não métricas como a música, arte, habilidades de liderança, compromisso social e escrita criativa.

Gardner (2000, p. 47), diante da necessidade de analisar o sujeito e sua inteligência sob uma nova óptica, definiu a inteligência como "um potencial biopsicológico, uma ou mais habilidades que direcionam para a resolução de problemas ou na criação de produtos significativos no espaço cultural". Dentro dessa perspectiva, o referido autor destaca as Inteligências Múltiplas (IM), sendo: Inteligência linguística; Inteligência musical; Inteligência lógico-matemática; Inteligência espacial; Inteligência corporal-cinestésica; Inteligência intrapessoal; Inteligência interpessoal e a Inteligência naturalista, que serão exploradas no decorrer deste artigo.

A terminologia Superdotação, Altas Habilidades, Talento, Dotação, Sobredotação, Altas Habilidades/Superdotação, gênio, prodígio e outros, são alguns termos adotados para identificar a pessoa que apresenta habilidades superiores. A existência de diferentes definições do termo, bem como a utilização como sinônimos terminológicos, finda por dificultar a identificação e a prática especializada. A definição de alunos com AH/SD, proposto pela Política Nacional de Educação Especial na Perspectiva da Educação Inclusiva (Brasil, 2008), caracteriza-se pelo potencial elevado em qualquer área, isoladas ou combinadas: capacidade intelectual, aptidão acadêmica, capacidade de liderança, potencial psicomotor e nas artes, elevada criatividade, envolvimento na aprendizagem e realização de tarefas em áreas de seu interesse.

A definição recomendada em documentos oficiais do Ministério da Educação está baseada nos pressupostos teóricos de Renzulli (1988), quando caracteriza a superdotação por meios de três agrupamentos de traços humanos:

[...] habilidades gerais ou específicas acima da média, elevados níveis de comprometimento com a tarefa e elevados níveis de criatividade. As crianças superdotadas e talentosas são aquelas que possuem ou são capazes de desenvolver estes conjuntos de traços e que os aplicam a qualquer área potencialmente valiosa do desempenho humano (Renzulli, 1988).

A heterogeneidade apresentada no grupo com AH/SD intensifica a discussão em torno de sua definição, para Winner (1998), na visão de Ourofino e Guimarães (Brasil, 2007), o superdotado é o indivíduo que apresenta um desempenho superior à média em uma ou mais áreas, comparados à população geral da mesma faixa etária, estando em desenvolvimento contínuo. Outro conceito que testifica a ideia do desenvolvimento contínuo, segundo os autores, refere-se a Silverman (2002), ao definir o superdotado como um sujeito que possui um desenvolvimento assincrônico entre habilidades intelectuais, psicomotoras, características afetivas e aspectos do desenvolvimento cronológico, criando uma experiência interna qualitativamente diferente do padrão normal.

No que se refere à concepção de dotação e talento, Gagné e Guenther (2012) evidenciam o Modelo Diferencial de Dotação e Talento diferenciando-os: 
Dotação - designa posse e uso de notável capacidade natural, "aptidão", em pelo menos um domínio de capacidade humana, a um grau que coloca o indivíduo entre pelo menos os 10\% superiores do grupo comparável.

Talento - implica alto nível de desempenho e mestria em habilidades e competências sistematicamente desenvolvidas, (conhecimento ou realização), em pelo menos um campo de atividade humana, a um grau que coloca o indivíduo entre $10 \%$ melhores no grupo etário exercendo aquela atividade (Gagné \& Guenther, 2012, p. 21).

Pérez e Freitas (2016), à luz das teorias de Renzulli (2014, 2016), afirmam que as habilidades acima da média caracterizam a capacidade de processamento da informação com a integração de experiências que resultam em respostas adaptativas às novas situações, podendo ser demonstradas em uma ou mais áreas de desempenho.

Para Renzulli (2018), a concepção de superdotação dos Três Anéis objetiva mostrar as principais dimensões do potencial humano para a produtividade criativa. Assim, a confluência entre a habilidade acima da média, a criatividade e o envolvimento com as tarefas possibilitam criar as condições para desenvolver o processo criativo e produtivo. Outro aspecto a ser considerado, segundo o autor, tange a criatividade e o compromisso com a tarefa, considerando-os, contextuais, situacionais e temporais, enquanto a inteligência geral, habilidades específicas e acadêmicas tendem a permanecer relativamente constantes.

O fenômeno das AH/SD é um fato presente no dia a dia da escola, pois o potencial do aluno superdotado pode manifestar-se de diferentes modos no contexto escolar, cabendo aos profissionais da educação conhecer os conceitos e indicadores para iniciar o processo de identificação desse alunado. A responsabilidade não está somente no professor, mas de toda a equipe pedagógica, pois é ela que propicia o suporte para que o professor possa desempenhar seu papel em sala de aula. Para Lima e Moreira (2018):

o aluno superdotado é identificado pela forma como aprende e expressa sua aprendizagem, seja nos aspectos acadêmicos, artísticos, psicomotores, dentre outros que possam apresentar. É por este motivo que considerar os indicadores de altas habilidades/superdotação, viabilizar serviços de atendimento específicos e adequados, e criar estratégias pedagógicas eficazes em sala de aula comum devem ser uma preocupação do professor, das coordenações e direções dos cursos, bem como dos demais envolvidos no processo pedagógico (Lima \& Moreira, 2018, p. 276).

O processo de identificação envolve a avaliação e o acompanhamento contínuo, sendo insuficiente basear-se em uma única fonte de informação. Considera-se importante esclarecer que a política pública educacional oportuniza a criação de programas, projetos e alternativas pedagógicas para atender a demanda de alunos com AH/SD, "mas sem que haja a identificação destes alunos, a demanda deixa de existir, o que descarta a evidência de um programa de atendimento" (Lima \& Moreira, 2018, p. 275). Portanto, conhecer e reconhecer os indicadores de AH/SD oportuniza o atendimento às peculiaridades da criança e proporciona um atendimento educacional especializado.

Para obtermos maior legitimidade no processo de identificação de AH/SD, faz-se necessário transpor diversas formas de ideologias, mitos e ideias equivocadas sobre as concepções de AH/SD. Pois este aluno poderá apresentar dificuldades acadêmicas, comportamentais, transtornos de aprendizagens e outros fatores que possam mascarar o potencial superior (Santos, 2019).

Os estudos de Sabatella (2012) reportam-se à algumas características que demostram habilidades, comportamentos e reações recorrentes em superdotados que podem ser observados por pais e professores. Entre eles estão a intensidade, sensibilidade, desenvolvimento moral, complexidade, profundidade e perfeccionismo. Segunda a autora, é natural para um superdotado envolver-se em situações e emoções de forma intensa, podendo ocasionar quadros de ansiedade, inadequação e inferioridade. O senso de justiça e a preocupação com problemas sociais também estão presentes nas 
características do superdotado, bem como a capacidade de aprender e processar informações complexas rapidamente.

Outras características dizem respeito à memória, a facilidade de focar em muitos assuntos e resolver questões ao mesmo tempo, a curiosidade e o anseio por novidade. Os alunos AH/SD buscam por atividades significativas ou intelectualmente desafiadoras e se desmotivam com a monotonia. $\mathrm{O}$ desafio de regras e autoridade caracterizado pela vontade de realizar e resolver de sua maneira os desafios, buscando novas abordagens para a resolução, a energia normalmente acompanha a alta inteligência, podendo parecer distraído ou desatento, pois está envolvido em diferentes atividades de seu interesse, iniciando muita coisa ao mesmo tempo (Sabatella, 2012, p. 118-127).

Na concepção de Perez e Freitas (2016), o indivíduo com AH/SD pode evidenciar um vocabulário mais elaborado que os demais colegas, capacidade analítica e indutiva e memória muito desenvolvida, destaque na área de seu interesse, pensamento abstrato e um raciocínio lógico-matemático muito desenvolvido. Na criatividade, destaca-se a curiosidade, ideias diferentes, criticidade, soluções, respostas incomuns e o gosto por desafios.

Estando a criatividade vinculada às AH/SD, Alencar et al. (2016) explicam que é necessário fortalecer as habilidades cognitivas do aluno, abrindo espaço para o ato de criar, não como algo exterior, mas parte da sua própria vivência, proporcionando atividades que estimulem a imaginação, pois as habilidades criativas podem ser desenvolvidas por meio de intervenções, treinamentos e/ou instruções.

Corroborando, Piske (2018) aponta que alunos com superdotação criativo-produtiva apresentam sensibilidade a detalhes, criatividade e originalidade, aversão às rotinas, procuram novas formas de solucionar problemas e pensam por analogias. Essas características são observáveis em sala de aula, devendo ser consideradas no processo de identificação de AH/SD.

Diante do exposto, é imprescindível a identifícação deste alunado, não por um simples título, mas para que receba o atendimento educacional especializado, possibilitando desenvolver suas habilidades na íntegra. Assim, os profissionais da educação necessitam ter conhecimento teórico sobre AH/SD, pois "a teoria é certamente o leme e a bússola que deveriam nos guiar em direções a praticas que evitam a aleatoriedade nas metas que buscamos" (Renzulli, 2018), para compreender os indicadores e elaborar práticas educativas interconectadas, criando ambiente desafiador e motivador aos superdotados, visto que os alunos com AH/SD necessitam de estímulos para identificar e aprimorar as suas potencialidades, caso não haja práticas educacionais adequadas, esses discentes dificilmente atingirão êxito em suas realizações (Sabatella, 2012).

\section{Enriquecimento extracurricular para alunos com AH/SD}

O AEE contribui para o processo de inclusão e a interconexão de saberes e práticas pedagógicas com o ensino comum, de modo a orientar o ensino e a aprendizagem, disponibilizando recursos para a complementação ou suplementação, fortalecendo os marcos legais de um sistema educacional inclusivo. Integrantes da Educação Especial, alunos com AH/SD dispõem de direitos ao AEE, ocorrendo no contraturno, na própria escola, em Sala de Recursos Multifuncional para Altas Habilidades/Superdotação (SRM-AH/SD) ou centro especializado que ofereça esse atendimento educacional.

Delpretto e Zardo (2010) destacam que os objetivos do AEE se definem por beneficiar a interação do aluno no contexto escolar, potencializar suas habilidades por meio do enriquecimento curricular, expandir o acesso ao uso de tecnologias digitais, promovendo a participação em atividades voltadas à prática de pesquisa e desenvolvimento de produtos, bem como estimular o desenvolvimento de projetos com temáticas diversificadas em áreas como esporte, ciências, artes e outras.

Nos documentos da Superintendência da Educação (SUED) e Secretaria de Estado de Educação (SEED), e representativos da educação especial paranaense, a Instrução no 010/2011 (SUED/SEED, 2011), dispõe que o professor da SRM-AH/SD, inicialmente, deverá identificar as necessidades educacionais dos alunos, elaborando assim, um plano educacional individualizado com metodologias e 
estratégias diferenciadas, de forma a atender individualmente ou em pequenos grupos de maneira flexível. O trabalho colaborativo, junto com o professor da classe comum, também deverá estar presente, para que assim sejam desenvolvidas práticas pedagógicas inclusivas.

A SRM-AH/SD deverá promover um ambiente propício para o desenvolvimento das múltiplas inteligências, da criatividade e a potencialidade. A ação pedagógica deverá constituir-se de procedimentos específicos, tendo por objetivo enriquecer a aprendizagem, oportunizando intervenções nas áreas das habilidades e interesses dos alunos, da mesma forma, promover o desenvolvimento intrapessoal e interpessoal (Instrução no 010/2011 - SUED/SEED).

Para Gardner (2010), cada pessoa tem capacidade de possuir todas as oito inteligências, porém, o que diferencia estas capacidades entre os indivíduos é o grau de desenvolvimento. Os potenciais dentro do espectro da inteligência dependem da motivação e dos recursos disponíveis, ocorrendo o enriquecimento das qualidades intelectuais pelas experiências vividas e praticadas. O autor considera que, independentemente do conteúdo, conceito ou ideia, se faz necessário apresentá-los de diversas formas para que possam ativar as diferentes inteligências ou combinações destas, pois "só os que conseguem pensar em um tópico de várias formas têm uma compreensão minuciosa desse tópico, aqueles cujo entendimento se limita a uma única visão têm uma compreensão frágil” (Gardner, 2010 p. 21).

Em sua teoria, Gardner (2010) ressalta a importância de desenvolver a capacidade de resolver problemas reais, utilizando-se de todas as inteligências. Assim, o espaço para a aprendizagem deve ser marcado por um ambiente estimulador que possibilite a cooperação e a interação entre aluno-aluno e aluno-professor, permitindo desenvolver o processo criativo e as múltiplas inteligências. Por isso, as práxis pedagógicas em SRM-AH/SD devem articular atividades para oferecer uma aprendizagem significativa, estando abertas aos diversos recursos que possam apresentar diferentes forma de aprender, respeitando e valorizando as habilidades de cada aluno.

Para Depizzol e Preto (2018), a utilização de entretenimento interativo, torna o aprendizado mais atrativo, permitindo que os estudantes desenvolvam suas potencialidades, busquem novas estratégias e soluções, adquirindo assim, conhecimentos diversificados e aperfeiçoamento do processo criativo e crítico. Neste contexto, as tecnologias digitais tornam-se um importante recurso, pois oportunizam a exploração de conteúdos de seu interesse, o compartilhamento de informações, propiciam expressar a criatividade, bem como para desenvolver a habilidade criativo-produtiva, aumentando a autonomia em seu processo de aprendizagem (Santos, 2019).

Para Smole (1999), à luz das inteligências múltiplas, todo o aluno tem potencial para se desenvolver intensamente em uma ou mais áreas, para que isso ocorra, faz-se necessário estimular diferentes habilidades dos indivíduos. E, para inserir as tecnologias digitais nas aulas, é necessário um mapeamento de interesses dos educandos e a seleção dos recursos determinando a qualidade e a sua contribuição no processo de aprendizagem "há centenas de sites, softwares, jogos e aplicativos que podem ser utilizados na área educacional, disponíveis no mercado e a internet. Ao elaborar uma atividade pedagógica com TDIC, inicialmente o professor precisa conhecer o recurso que será utilizado" (Chacon \& Pedro, 2016, p. 09). Portanto, as tecnologias digitais não promovem o enriquecimento por si, cabe ao professor definir meta e objetivos educacionais a serem com elas alcançados.

As sugestões propostas neste artigo são exemplos dos diferentes tipos de recursos digitais que poderão ser utilizados em sala de aula objetivando o estímulo, a discussão, o compartilhamento e a produção de ideias e conteúdo, podendo ser adaptados aos diferentes níveis escolares e estilos de aprendizagem. 


\subsection{Inteligência Linguística e Naturalista}

A espontaneidade, a sensibilidade para sons, ritmos, a capacidade de relatar as experiências ricas em detalhes e a habilidade de entusiasmar, convencer, demonstrar os sentimentos e persuasão, por meio da oralidade e a escrita (Gadner, 1995; Vieira, 2005), são característica evidenciadas em alunos que apresentam AH/SD na área da linguagem. Desta forma, o trabalho em SRM-AH/SD deverá promover um ambiente que possibilite desenvolver o processo de leitura e escrita, que favoreça desenvolver a imaginação, estimule o processo criativo sobre diversos temas, pois as atitudes do professor contribuem de forma significativa com o aluno para o seu desenvolvimento social, cognitivo e afetivo, como também no entusiasmo pela busca de novos conhecimentos (Alencar, 2016).

Os recursos digitais, ora apresentados, objetivam contribuir, de maneira diversificada, na produção de História em Quadrinhos (HQ). Este gênero discurso possui uma linguagem consolidada, pois está presente desde os anos iniciais, favorecendo assim, o reconhecimento e sua estrutura textual, elipse temporal, balão, a onomatopeia e outros subsídios para o desenvolvimento da narrativa.

Os recursos como Pixton ${ }^{1}$, ToonDoo ${ }^{2}$, Strip Creator $^{3}$ e Make Beliefs Comix ${ }^{4}$ são algumas plataformas para a criação de HQ que disponibilizam templates, personagens e expressões faciais que poderão ser exploradas pelo professor, por meio de debates e discussões acerca de diversos temas. Ressalta-se que, para se produzir um texto, segundo Geraldi (2003, p. 137) é preciso que "(a) se tenha o que dizer. (b) se tenha uma razão para dizer o que se tem a dizer. (c) se tenha para quem dizer o que se tem a dizer. (d) o locutor se institua como tal, enquanto sujeito que diz o que diz para quem diz".

No processo de escrita, as tecnologias digitais como ferramentas de autoria que, segundo Silva (2013, p. 31), correspondem um "aplicativo equipado com diversas ferramentas de multimídia que, a partir de modelos pré-definidos, permitem ao usuário inserir informações, imagens e sons, promovendo a autonomia e estimulando o desenvolvimento cognitivo de quem cria atividades a partir dele", podem estimular a participação ativa e colaborativa entre os alunos com AH/SD, propiciando o compartilhamento e a soma de conhecimento em sala de aula.

Apresentar desafios e situações-problema que estimulem a imaginação e a fantasia são formas de incentivar e desenvolver a criação de um produto de forma autônoma, enriquecer o ensino, possibilitar reflexões críticas sobre o contexto e intenção de produção, ampliando a visão de mundo e a responsabilidade social, resultando em uma aprendizagem significativa que potencializa a autonomia e a autoria.

Assim, as narrativas digitais ou storytelling possibilitam trabalhar de forma interligada com diversos conteúdos e disciplinas, atendo o estilo de aprendizagem de cada aluno. As narrativas, que eram tradicionalmente orais ou escritas, tomam um novo formato sendo produzidas com uma combinação de mídias como imagens, vídeos, áudios, possibilitando novas formas de produção, contribuindo para a diversidade de representação de conhecimento. Almeida e Valente (2012) ratificam:

A narrativa é a criação que o contador de história usa para fazer sentido do mundo e da sua experiência. É um dos quatro modos retóricos, além da exposição, argumentação e descrição; um dos formatos construtivos para descrever uma sequência de eventos [...] a narrativa é composta de um início para captar a atenção do leitor ou ouvinte, o meio que desenvolve a trama dos personagens, que não precisa ser necessariamente uma pessoa, mas pode ser um fenômeno, uma comunidade. Finalmente a trama é resolvida ou explicada e, assim, é apresentada a parte final (Almeida \& Valente, 2012, p. 333-334).

\footnotetext{
${ }^{1}$ Disponível em http://www.pixton.com/br. Acesso 04 mar. 2021.

2 Disponível em http://www.toondoo.com. Acesso 04 mar. 2021.

${ }^{3}$ Disponível em http://www.stripcreator.com/make.php. Acesso 04 mar. 2021.

${ }^{4}$ Disponível em www.makebeliefscomix.com. Acesso 04 mar. 2021
} 
Para Prado et al. (2017, p. 1172), “o uso de narrativas digitais induz à criatividade, à autonomia e à participação, algo que sempre buscamos em nossos discursos pela educação de qualidade, mas que ainda se encontram em um plano teórico na realidade escolar". Os autores complementam que, por meio desta produção, o aluno desempenha o papel ativo no processo de construção, trilhando o conhecimento e interagindo com seus pares, em um processo colaborativo de aprendizagem.

Plataformas como Powtoon ${ }^{5}$, UtellStory, ${ }^{6}$ Xtranormal $^{7}$ e StoryBird ${ }^{8}$ permitem a criação de apresentações e contação de histórias que englobam sons, vídeos, imagens e textos, incluindo um conjunto de personagens e cenários. A estimulação das habilidades na área da linguagem, tanto na oralidade quanto na escrita, requer estratégias que possibilitem o desenvolvimento e o aprimoramento constante.

Cabe ao professor propor atividades em que as habilidades possam ser desenvolvidas de forma a criar condições para que o aluno expresse o pensamento criativo e resulte em produtos, como as storytelling, envolvendo temas sugeridos e/ou de seu interesse, e, portanto, está relacionada com uma narrativa, a capacidade e a habilidades de contar histórias (biografias, entrevistas, histórias de vida entre outros) de modo envolvente e estimulador (Santos, 2019).

Outro recurso digital são as ferramentas de criação de figuras animadas, do inglês Graphics Interchange Format (GIF), que possibilita desenvolver a produção criativa de conteúdos capazes de envolver e ampliar os conhecimentos sobre diversos assuntos, em diferentes situações. O GIF animado armazena uma série de imagens em um único arquivo, exibindo-as em sequência, de forma automática e em loop. Para criar uma animação, é necessário providenciar uma série de imagens com pequenas diferenças de posição, formato ou cor entre os elementos que compõem a cena.

De acordo com Nadal (2014, p. 38), “um GIF pode então circular por diferentes pontos da rede e se transformar em vários discursos a partir de ambientações, manipulações e curadorias", de forma que as imagens digitais produzidas com uma intencionalidade são manipuladas por outro sujeito em diferentes contextos. Para Almeida (2015), os GIF transmitem as sensações cotidianas e representam emoções, por meio da sua animação e de seu ritmo partindo de seus frames, funcionam ainda como manifestações coletivas que acabam por estabelecer grupos de interesses.

A sua produção pode contribuir no desenvolvimento da criatividade, interpretação de discursos e intencionalidade da linguagem, além de revelar contextos inovadores na área da linguagem, por envolver, mutuamente, imagens, sons e textos escritos. Assim, o processo criativo de um GIF requer a organização de ideias, a sequência lógica de um assunto e a coerência na disposição de imagens (Santos, 2019).

Para agregar às atividades de enriquecimento, a linguagem das animações, vídeos e filmes permitem uma abordagem prática e dinâmica de produção de conteúdo, projetos e atividades colaborativas, possibilitando abordar informações em curto espaço de tempo, viabilizando o compartilhamento de experiências e conhecimentos. Para Melo (2018, p. 63), os recursos audiovisuais "são, por natureza epistêmica, transdisciplinares, interdisciplinares e multidisciplinares, e provocam rupturas na disciplinaridade do conhecimento", favorecendo o trabalho em várias áreas do conhecimento.

Os temas podem surgir do interesse do aluno e/ou incluir referências culturais, documentários sobre meio ambiente, favorecendo a estimulação da Inteligência Naturalista, que visa "diferenciar e reconhecer membros de uma espécie; mapear, formal ou informalmente, as relações existentes entre as várias espécies" (Vieira, 2005, p. 9).

As crianças que apresentam esta inteligência demonstram "uma relação apaixonada e intensa com a natureza, em um sentimento de pertencimento e cuidado com os ecossistemas e habitats, com os animais e as plantas, para além de sua utilidade econômica ou estética" (Carneiro \& Lacerda, 2018). Este

\footnotetext{
${ }^{5}$ Disponível em: https://www.powtoon.com. Acesso 04 mar. 2021.

${ }^{6}$ Disponível em: https://www.utellstory.com. Acesso 04 mar. 2021.

${ }^{7}$ Disponível em: http://www.xtranormal.com. Acesso 04 mar. 2021.

${ }^{8}$ Disponível em: https://storybird.com. Acesso 04 mar. 2021.
} 
interesse pela fauna e flora possibilita desenvolver atividades de observação, consciência ecológica, pesquisa e experiências que possam ser compartilhadas em redes sociais e canais de comunicação.

A aplicação desse recurso em sala de aula requer a orientação para a elaboração de um roteiro que organize as informações e recursos que serão utilizados visualmente e sonoramente. A produção de vídeo comporta narrações, áudios e técnicas de animação, proporcionando a capacidade de captar a atenção, por meio da memória visual e sonora, podendo ser utilizados instrumentos como filmadora, o smartphone/tablet ou computador/notebook com webcam.

Portanto, o processo de produção de diversos gêneros discursivo, a relação entre a troca de ideias, de informações e conhecimento enriquecem e despertam potenciais para a criação. O compartilhamento destas produções, para a comunidade escolar, é imprescindível.

\section{2 .2 Inteligência Lógico-matemática e Espacial}

A Inteligência Lógico-matemática é a capacidades de solucionar problemas envolvendo números e elementos como cálculos, levantamento e averiguação de hipóteses, podendo estar relacionada com a Inteligência Espacial, responsável pela capacidade de orientar, de criar, transformar ou modificar imagens, construir ideias visuais e espaciais (Gardner, 1995; Vieira, 2005). Por este motivo, os recursos digitais sugeridos, nessa subseção, possibilitam o desenvolvimento destas habilidades, de forma concomitante, por proporcionarem o contato com atividades que demandam raciocínio lógico e habilidade em criar e modificar determinado espaço.

Para o desenvolvimento da Inteligência lógico-matemática e a espacial, as atividades elaboradas deverão envolver situações que possibilitem a resolução de problemas e o uso de estratégias diferenciadas, bem como a construção de ideias de ordem espacial, entre elas, a capacidade de recriar experiências visuais sob diversas formas.

Gee (2003) ressalta que os jogos são especificamente projetados para permitir que os jogadores, nos níveis iniciais, tenham contato com problemas de fácil resolução, comparando os níveis iniciais como tutoriais ocultos. Essa escala de dificuldade favorece, segundo o autor, a resolução de problemas no decorrer do jogo, pois, caso a criança encontre muita dificuldade para iniciar o jogo, poderá ocorrer a desmotivação em jogar e, consequentemente, desmotivação na aprendizagem.

As habilidades de projetar, combinar e organizar espaços podem ser desenvolvidas a partir do jogo Minetest ${ }^{9}$. Esse recurso digital propõe a construção de um mundo a partir da exploração do ambiente, coleta de blocos e objetos para sobrevivência. O Minetest possibilita a utilização de diversas habilidades para a sua construção, abrindo possibilidades para o desenvolvimento de projetos e abordagens de diversos conteúdos. O software de autoria é um recurso útil para que o enriquecimento pedagógico em SRM-AH/SD ocorra de maneira lúdica e criativa.

Em conformidade com os estudos de Silva et al. (2016, p. 2480), “as ferramentas de autoria são softwares que permitem que um usuário possa criar aplicações em diversas áreas, utilizando recursos de imagens, textos, vídeos e sons, entre outros", não necessitando que o aluno ou professor tenham conhecimentos aprofundados de programação. Para Kaminski (2018, p. 20), o aluno "tem o desejo de criar, de interagir e de produzir, uma vez que esse contexto cultural, já há algum tempo, permite que qualquer sujeito seja não apenas consumidor de informações e/ou conhecimento, mas também produtor por meio das tecnologias digitais".

Desta maneira, alguns recursos permitem ao aluno desenvolver a capacidade de interação, iniciativa, raciocínio e criatividade, com ênfase em ferramentas de programação - ou de desenvolvimento do Pensamento Computacional (PC), que pode ser definido como um processo de resolução de problemas, envolvendo o projetar, planejar, ordenar e analisar cada situação, incluindo uma gama de

${ }_{9}^{9}$ Disponível em https://www.minetest.net. Acesso 05 mar. 2021. 
ferramentas mentais (Wing, 2006). Para Brackmann (2017), o processo do PC é composto por quatro pilares: decomposição, reconhecimento de padrões, abstração e algoritmos objetivando a resolução de problemas. Assim, complementa o autor que:

\begin{abstract}
Pensamento Computacional envolve identificar um problema complexo e quebrá-lo em pedaços menores e mais fáceis de gerenciar (DECOMPOSIÇÃO). Cada um desses problemas menores pode ser analisado individualmente com maior profundidade, identificando problemas parecidos que já foram solucionados anteriormente (RECONHECIMENTO DE PADRÕES), focando apenas nos detalhes que são importantes, enquanto informações irrelevantes são ignoradas (ABSTRAÇÃO). Por último, passos ou regras simples podem ser criados para resolver cada um dos subproblemas encontrados (Algoritmos) (Brackmann, 2017, p. 893).
\end{abstract}

Alguns recursos digitais permitem a autoria como cratch $^{10}$, programa de programação visual e multimídia, destinado à criação e promoção de sequências animadas para a aprendizagem de programação, sendo possível trabalhar com imagens, fotos, música, criar desenhos, mudar aparência, fazer com que os objetos interatuem. O Game Edito ${ }^{11}$, ferramenta multimídia interativa de código aberto para desenvolvimento de jogos, com uma interface simples e intuitiva e um rico conjunto de recursos que permite desenvolver jogos 2D para computadores pessoais e dispositivos móveis.

Segundo Gee (2003), um bom jogo constitui-se, entre outras características, na quantidade e qualidade do envolvimento do jogador em manipular e decidir o futuro da personagem - sentindo-se parte do jogo, terá maior motivação em elaborar estratégias para a resolução de problemas. Portanto, o aluno, ao criar seu próprio jogo, programando e coordenando cada nível de dificuldade, tem a oportunidade de desenvolver habilidades e inteligências, tanto lógico-matemática e espacial, quanto linguística, intrapessoal e interpessoal, levando em conta que fatores como a liderança, a responsabilidade social e emocional aplicados na produção do jogo influenciam na qualidade do produto.

Silva et al. (2015) elencaram três habilidades exploradas sobre o ensino e aprendizagem de programação nas escolas, sendo habilidade cognitiva, caracterizada pela resolução de problemas, raciocínio lógico e tomada de decisão; habilidade social, correspondente à cooperação, elaboração de regras, e habilidade emocional, como autoestima, autoconfiança e autoavaliação. A criatividade, a estruturação do pensamento, responsabilidade, curiosidade, confiança e trabalho em equipe também são competências desenvolvidas com atividades de programação.

O alinhamento do PC com o planejamento das aulas contribuirá para o estímulo da prática do raciocínio e da resolução de problemas, pois a estratégia de separar em partes cada problema, bem como planejar todas as etapas antes de colocá-lo em prática foram essenciais no resultado. A plataforma Programaê ${ }^{12}$, é um recurso que introduz a linguagem de programação num encaixe sequencial de blocos de comando. Já o LightBot ${ }^{13}$ é um jogo de quebra-cabeça baseado em codificação que oportuniza a aprendizagem lógica de programação de forma lúdica.

Por necessitar de um ensino dinâmico e estimulante focado em desafios, o professor poderá utilizar estes processos para mediar atividades de enriquecimento, visto que o software de autoria proporciona a liberdade de escolha de temas para a pesquisa e a mediação para o desenvolvimento científico, ampliando sua forma de aprender e desenvolver o pensamento crítico, criativo e produtivo.

\footnotetext{
10 Disponível em https://scratch.mit.edu/. Acesso 13 mar. 2021.

${ }^{11}$ Disponível em http://game-editor.com. Acesso 13 mar. 2021.

${ }^{12}$ Disponível em http://programae.org.br/hora-do-codigo/. Acesso 13 mar. 2021.

${ }_{13}$ Disponível em http://lightbot.com/flash.html. Acesso 13 mar. 2021.
} 


\title{
2.3 Inteligência corporal-cinestésica, interpessoal e intrapessoal
}

A inteligência corporal-cinestésica se manifesta pela capacidade de resolver problemas ou elaborar produtos utilizando o corpo ou partes do mesmo (Gardner, 1995). Pessoas com esta inteligência apresentam capacidades de manipular objetos com extrema habilidade, percepção do paladar (gourmets, chefes de cozinha) e movimentos expressivos em respostas aos diferentes ritmos musicais ou habilidades corporais atléticas (Vieira, 2005).

As atividades para o desenvolvimento das inteligências, além dos jogos interativos, podem ocorrer pela Robótica Educacional, por apresentarem situações que permitem que a criança possa manipular e controlar objetos concretos e, por meio destes objetos, observar a materialização dos comandos dados por ela ao computador, processo a partir do qual se estabelece a construção do seu conhecimento (Santos, 2019).

Para Zilli (2004), a robótica contempla o desenvolvimento da motricidade fina e a formação de habilidades manuais, bem como proporciona uma atividade dinâmica para a construção da autonomia, independência e responsabilidade. No que se refere às Inteligências Múltiplas, a autora expõe que:

\begin{abstract}
além do desenvolvimento da inteligência lógico-matemática que é a mais evidente, pelo fato de trabalhar com a programação de computadores e cálculos em geral, promove o desenvolvimento da inteligência linguística, interpessoal, intrapessoal e até da espacial, pois envolve aspectos como o trabalho em grupo, planejamento de ações, projeto do modelo a ser construído, reconstrução do modelo e apresentação do resultado (Zilli, 2004, p. 77).
\end{abstract}

Tanto a Inteligência interpessoal, "capacidade de compreender os outros e trabalhar com eles" (Gardner, 1995, p. 15), quanto a Inteligência intrapessoal, capacidade que nos permite "compreender a nós mesmos e trabalhar conosco" (Gardner, 1995, p. 15), são estimuladas nas atividades propostas com as tecnologias digitais, visto que a colaboração mútua para a resolução de problemas e a autonomia na criação de produtos perpassam todas as etapas de elaboração.

Desta forma, integrar a prática pedagógica com a construção de protótipos ou dispositivos robóticos, como meio de resolução de problemas, possibilita estimular a criatividade dos alunos que "interagem, trocam ideias, testam hipóteses construindo e desconstruindo seus protótipos em busca da solução ao problema apresentado" (Fornaza et al., 2015, p. 142), neste processo "aprendem, se socializam e desenvolvem um trabalho cooperativo com a divisão de tarefas para a construção do protótipo" (Fornaza et al., 2015, p. 142).

Para Queiroz et al. (2016, p. 2087), “a Robótica permite que os alunos trabalhem uma grande diversidade de competências e habilidades à medida que engloba, em um único objeto de estudo, diversas áreas do conhecimento [...]", viabilizando a manipulação e controle de objetos concretos pela criança sendo que, por meio da observação e a materialização dos comandos programados por ela ao computador, são estabelecidos os processos de construção do conhecimento.

Silva et al. (2018) relatam uma experiência de ensino utilizando a plataforma de prototipação Arduino ${ }^{14}$, que oferece código aberto baseada em hardware e software fáceis de usar, para escrever código na linguagem de programação, materiais recicláveis como potes de manteiga, papelão, papel EVA e papéis-rascunho, além de outros componentes eletrônicos para a montagem de carros robôs de futebol seguindo a contextualização de uma narrativa digital.

Após a construção dos protótipos, os alunos participaram de um jogo de futebol utilizando suas criações e, por esta investigação, os autores observaram maior interesse, motivação e dinamismo na execução das tarefas. A robótica educacional desencadeou também o engajamento dos alunos, o trabalho colaborativo e o compartilhamento de conhecimentos.

\footnotetext{
${ }^{14}$ Disponível em: https://www.arduino.cc/. Acesso 13 mar. 2021.
} 
Portanto, os projetos envolvendo a robótica e a linguagem de programação contribuem para o desenvolvimento do raciocínio lógico, formulação de hipótese, habilidades manuais e estéticas, nas relações interpessoais e intrapessoais, bem como, nos conceitos apreendidos em diversas áreas do conhecimento. Para Alencar et al. (2016), quando o ambiente escolar possibilita a fantasia e a imaginação, a partir de um núcleo comum de conhecimento, os alunos são estimulados a criar a sua própria visão sobre o que lhes é ensinado. Assim, estes são encorajados a compartilhar impressões e referências.

\subsection{Inteligência Musical}

A inteligência musical "é aquela que possibilita a compreensão, discriminação, percepção, expressão e transformação das formas musicais (ritmo, tom, melodia, timbre dos sons)" (Gardner, 1995; Vieira, 2005).

Para o estímulo da inteligência, o professor da SRM-AH/SD deve proporcionar atividades que despertem a percepção auditiva da criança, como brinquedos cantados, músicas de diversas culturas e jogos com diferentes timbres que possibilitem a discriminação dos sons, ritmos e outros, contemplando o universo em que está inserida, pois, segundo Chamorro et al. (2017), a música pode ajudar a desenvolver a concentração, raciocínio, disciplina pessoal, além de proporcionar à criança o momento de expressar seus sentimentos e ideias.

Para Carneiro e Lacerda (2018, p. 134), “a inteligência musical é uma estância cognitiva que pode envolver e, consequentemente, refinar outros tipos de inteligências" contribuindo para um desenvolvimento global do aluno. Complementam os autores:

Afetivamente, a arte musical amplia a consciência do sujeito por meio do contato consigo mesmo e com o outro. Ouvir, analisar e reconhecer a sua produção sonora, negá-la ou acolhê-la é um gesto de autoconhecimento e consciência de suas potencialidades e dificuldades, ao mesmo tempo em que expande a criatividade (Carneiro \& Lacerda, 2018, p. 134).

A música proporciona o desenvolvimento de outras inteligências, como a inteligência lógicomatemática. $\mathrm{O}$ uso e a leitura de gráficos e esquemas, como os áudios partituras e as partituras convencionais, são importantes para a fluência do pensamento lógico, sendo que a execução de padrões rítmicos estimula o raciocínio por lidar diretamente com regulações temporais, classificação, comparação e a dedução, além das relações entre a duração rápido/lento, grave/agudo, entre outros (Carneiro \& Lacerda, 2018).

Os autores supracitados relacionam a música com as inteligências intrapessoal e interpessoal, pois a música torna-se um meio não verbal de comunicação e percepção do outro nas criações musicais - as crianças poderão aprender a ponderar seus impulsos, o tempo, a ansiedade e o medo em suas produções, percebendo o importante papel do outro tanto na percepção e orientação do trabalho, quanto na troca de ideias e conhecimentos. O conhecimento e a deferência frente às manifestações sonoras de outras culturas oportunizam o trabalho sobre o respeito de julgamentos antecipados e do estabelecimento de rótulos e preconceitos, principalmente no tocante a estilos e estéticas musicais.

Desta maneira, as atividades de exploração e expressão como cantar, tocar algum instrumento, utilizar objetos e o próprio corpo musicalmente, o contato com a dança de diferentes culturas podem influenciar positivamente o desenvolvimento cognitivo da criança. Como recurso, sugere-se o software SOLFEGE 3.22.015, um programa para treinamento auditivo, de intervalos, acordes e teoria musical.

\footnotetext{
${ }^{15}$ Disponível em https://sourceforge.net/projects/solfege/. Acesso 13 mar. 2021.
} 
Outras sugestões são: $\mathrm{LMMS}^{16}$, que permite produzir música por meio de melodias e batidas, sintetizando e mixando sons, e Musescore ${ }^{17}$, software para notação musical.

Os jogos como o DÓ RÉ MI ${ }^{18}$, Notas Musicais ${ }^{19}$, Piano Online ${ }^{20}$ e Chrome Music Lab ${ }^{21}$ o também oferecem recursos produtivos para atividades com alunos com $\mathrm{AH} / \mathrm{SD}$ de diferentes áreas, pois possibilitam, de maneira lúdica, aprender e/ou aperfeiçoar seu contato com os elementos da música (partitura, notas musicais e outros), auxiliando no desenvolvimento cultural e psicomotor, na integração de diferentes linguagens e instrumentos musicais.

As sugestões ressaltadas não têm por objetivo formar músicos, mas proporcionar aos alunos a oportunidade de utilização das tecnologias digitais como fonte de pesquisa, estímulo e ludicidade, visto que, ao brincar, a criança expressa seus sentimentos, desejos, dificuldades (Piske \& Stoltz, 2018) e a criatividade.

\section{Considerações finais}

Alunos com AH/SD necessitam de acompanhamento educacional especializado para que possam desenvolver suas habilidades. Para isso, a escola precisa ser instrumentalizada para atender sua intrisidade. Ter conhecimento sobre os conceitos da temática em questão desmistifica a associação equivocada das $\mathrm{AH} / \mathrm{SD}$ ao desempenho escolar excepcional, a ausência de dificuldades de aprendizagem e o não reconhecimento de suas necessidades educacionais.

Sabe-se que potencial elevado em área acadêmica, intelectual, psicomotora e artes não se manifesta da mesma forma em todos os indivíduos. Portanto, o investimento na formação e qualificação de professores é fundamental para as práticas inclusivas.

O ambiente de aprendizagem necessita ser dinâmico, motivador e seguro, este último no sentido de permitir que o aluno possa expor suas ideias, seu processo de criação, originalidade e anseios individuais. Para isso, as práticas pedagógicas em SRM-AH/SD devem articular recursos que proporcionam o desenvolvimento cognitivo do aluno, de forma lúdica. Atividades que envolvem protagonismo, autoria e resolução de problemas são sugeridas pela criação de vídeos, GIF, storytelling, jogos de raciocínio, pensamento computacional e outros recursos, tal que o aluno com AH/SD tenha condições de expressar sua criatividade, opinião e uma diversidade de conceitos e pensamentos.

O processo de produção e a relação entre a troca de ideias, de informações e conhecimento enriquecem e despertam potenciais. O compartilhamento das produções desenvolve a responsabilidade na criação, abarcando o compromisso de como, o que, para quem produzir, e qual a intenção desta produção.

As atividades supracitadas são possíveis alternativas para a estimulação de diferentes inteligências e habilidades, pois aluno com AH/SD necessita de estratégias criativas e inovadoras que tornem o ambiente escolar desafiador e motivador. Os recursos digitais explicitados podem favorecer o protagonismo do aluno, proporcionando a aprendizagem de novos conceitos e desenvolvendo habilidades para a resolução de problemas.

As tecnologias digitais, quando aplicadas de forma planejada e com objetivos pedagógicos claros, podem propiciar estímulos que direcionam o aluno a pensar em soluções, a explorar possibilidades, colaborando para o amadurecimento de hipóteses, uma vez que possibilitam o acesso a diferentes informações e mídias, além de conteúdos interativos e dinâmicos.

\footnotetext{
${ }^{16}$ Disponível em https://www.ufrgs.br/soft-livre-edu/wiki. Acesso 13 mar. 2021.

${ }^{17}$ Disponível em https://musescore.org/pt-br. Acesso 13 mar. 2021.

${ }_{18}$ Disponível em http://www.escolagames.com.br/jogos/doReMi/. Acesso 13 mar. 2021.

${ }_{19}^{19}$ Disponível http://www.jogosonlinegratis.org/jogoonline/jogos-de-notas-musicais/. Acesso 13 mar. 2021.

${ }^{20}$ Disponível em http://www.jogos360.com.br/real_piano_online.html. Acesso 13 mar. 2021.

${ }^{21}$ Disponível em https://musiclab.chromeexperiments.com. Acesso 13 mar. 2021.
} 
Há a necessidade de continuar investigando sistematicamente o uso de tecnologias digitais em SRM-AH/SD, de forma a criar subsídios que auxiliem os professores na aplicação dessas em suas práticas pedagógicas e, coletando mais evidências acerca do pressuposto de enriquecimento das potencialidades no alunado pelo uso sistêmico e planejado, relacionado a conteúdos e resolução de problemas.

\section{Referências}

Alencar, E. M. L. S., Braga, N. P., \& Marinho, C. D. (2016). Como Desenvolver o Potencial Criador: um guia para a liberação da criatividade em sala de aula (12a ed.). Petrópolis: Rio de Janeiro. Vozes.

Almeida, M. E. B., \& Valente, J. A. (2012, set/dez.). Integração Currículo e Tecnologias e a Produção de Narrativas Digitais. Revista Currículo sem Fronteira (v. 12, n. 3, pp. 57-82). Recuperado 03 dezembro, 2020, de www.curriculosemfronteiras.org.

Almeida, M. L. (2015). GIFS: Educação Estética, Afeto e Ativismo Através da Imagem Animada. Dissertação (Mestrado em Artes Visuais), Universidade Federal de Pelotas, Pelotas, Brasil.

Boyd, D., \& Bee, H. (2011). A criança em crescimento. Porto Alegre: Artmed.

Brackmann, C. P. (2017). Desenvolvimento do Pensamento Computacional através de Atividades Desplugadas na Educação Básica. Tese (Doutorado em Informática na Educação), Universidade Federal do Rio Grande do Sul, Porto Alegre, Brasil. Recuperado 03 dezembro, 2020, de http://www.lume.ufrgs.br/handle/10183/172208.

Brasil. (2008). Politica Nacional de Educação Especial na perspectiva da Educação Inclusiva. Brasília: Ministério da Educação, Secretaria de Educação Especial. Recuperado em 02 dezembro, 2020, de http://portal.mec.gov.br/docman/dezembro-2014-pdf/16690-politica-nacional-de-educacao especialna-perspectiva-da-educacao-inclusiva-05122014.

Brasil. (2010). Manual de Orientação: Programa de Implantação de Sala de Recursos Multifuncionais. Brasília: Ministério da Educação Secretaria de Educação Especial. Recuperado em 02 dezembro, 2020, de http://portal.mec.gov.br/docman/fevereiro-2012-pdf/9936manual-orientacao-programa-implantacaosalas-recursos-multifuncionais.

Carneiro, S. G. O., \& Lacerda, A. D. (2018). Educação Musical e Psicopedagogia: Caminhos para o Desenvolvimento das Inteligências Múltiplas. Revista PAIDE'LA (ano XIII, n. 19). Recuperado 30 novembro, 2020, de http://www.fumec.br/revistas/paideia/article/view/6321/3135.

Chamorro, A., Gitahy, R. R. C., Terçarial, A. A. L., \& Santos, D. A. N. (2017, jul./dez.). Educação Musical e as Tecnologias: O Uso de Objetos de Aprendizagem e Percepção dos Docentes. Revista Educação e Linguagens (v. 6, n. 11). Recuperado 04 março, 2021, de http://www.fecilcam.br/revista/index.php/educacaoelinguagens/article/viewFile/1651/1055.

Delpretto, B. M. L., \& Zardo, S. P. (2010). Alunos com Altas Habilidades/Superdotação no Contexto da Educação Inclusiva. In: DELPRETTO, B. M. L.; GIFFONI, F. A.; ZARDO, S. P. A Educação Especial na Perspectiva da Inclusão Escolar: Altas Habilidades/Superdotação. Brasília: Ministério da Educação, SEESP; Fortaleza. Universidade Federal do Ceará (v. 10, p. 23). 
Depizzol, F., \& Pedro, K. M. (2018). No caminho da autoria: criação de jogos educativos no PowerPoint por estudantes com altas habilidades ou superdotação. InFor, Inov. Form., Rev. NEaD-Unesp, São Paulo (v. 4, n. 1, pp. 2-20). Recuperado 11 março, 2021 de o https://ojs.ead.unesp.br/index.php/nead/article/download/461/artigo1_infor_v4n1_2018.

Fornaza, R., Webber, C. G., \& Villas-Boas, V. (2015). Kits Educacionais de Robótica: Opções para o Ensino de Ciências. Scientia Cum Industria (v. 3, n. 3, pp. 142-147). Recuperado 30 novembro, 2020 de http://www.ucs.br/etc/revistas/index.php/cientiacumindustria/article/.

Freitas, S. N. (2012). Altas Habilidades/Superdotação: Processos de Mediação com a Utilização das Tecnologias de Informação e Comunicação. In: Giroto, C. R. M., Poker, R. B., \& Omote, S. (Org.). As Tecnologias nas Práticas Pedagógicas Inclusivas. Cultura Acadêmica (vol. 1, pp. 185-210). Ed. São Paulo.

Gagné, F.; Guenther, Z. C. (2012). Desenvolvendo Talentos: Modelo Diferenciado De Dotação E Talento - Dmgt 2.0. In: Moreira, L.C, \& Stoltz, T. (Org.). Altas Habilidades/Superdotação, Talento, Dotação e Educação. (pp. 20-44, 2012). Curitiba: Juruá.

Gardner, H. (1995). Inteligências Múltiplas: A Teoria na Prática. Porto Alegre: Artes Médicas.

Gardner, H. (2020). Inteligência: um conceito reformulado. Rio de Janeiro: Objetivo.

Gardner, H., CHEN, J. Q., \& MORAN, S. (2010). Inteligências Múltiplas ao Redor do Mundo. Porto Alegre: Artmed.

Gee, J. P. (2003, out.). What Video Games Have to Teach us About Learning and Literacy. ACM Computers in Entertainment (v. 1, n. 1).

Geraldi, J. W. (2003). Portos de Passagem. São Paulo: Martins.

Kaminski, M. (2018). Análise das Práticas Pedagógicas na Educação da Escola Municipal Aloys João Mann Cascavel/PR. 2018. Dissertação (Mestrado em Ensino), Universidade Estadual do Oeste do Paraná, Foz do Iguaçu, PR, Brasil.

Lima, D. M M. P., \& Moreira, L. C. (2018). O Professor Frente à Identificação do Estudante com Altas Habilidades/Superdotação na Universidade. In: VIRGOLIM, A. (Org.) Altas Habilidades/Superdotação: Processos Criativos, Afetivos e Desenvolvimento de Potenciais (pp. 271-286). Curitiba: Juruá.

Melo, M. A. V. (2018). O uso pedagógico do audiovisual. Revista Discurso e Imagem Visual em Educação. João Pessoa (v. 3, n. 1, pp. 38-65).

Nadal, H. D. (2014). A cultura do Gif: Reconfigurações de Imagens Técnicas a partir dos Usos e Apropriações de Narrativas Cíclicas. Dissertação (Mestrado em Comunicação e Linguagens), Universidade Tuiuti do Paraná, Curitiba, Paraná.

Ourofino, V. T. A. T., \& Guimarães, T. G. (2007). Características Intelectuais, Emocionais e Sociais do Aluno com Altas Habilidades/Superdotação. In: FLEITH, D. S. (Org.). A Construção de Práticas Educacionais para Alunos com Altas Habilidades/Superdotação(V. 1, pp. 41-42). Brasilia: MEC/ SEESP. 
Paixão, W. P., Neto, C. S. S., Costa, R. J. S., \& Ladeira, F. S. (2016, out.). Jogos educativos e ferramentas de autoria multimídia: um estudo exploratório sobre quebra-cabeças digitais no contexto do ensinoaprendizagem. Congresso Brasileiro de Pesquisa e desenvolvimento em design (pp. 2478-2488). Recuperado 14 dezembro, 2020, de https://www.researchgate.net/publication/311459994_jogos_ educativos _e_ferramentas_de_autoria_multimidia_um_estudo_exploratorio_sobre_quebracabecas_digitais_no_co ntexto_do_ensino.

Paraná. (2011). Instrução no 010/2011 - SUED/SEED, Secretaria de Estado de Educação. Superintendência da Educação. Recuperado 01 dezembro, 2020, de www.educacao.pr.gov.br/ arquivos/File/... /Instrucao0102011seedsued.PDF.

Pérez, S. G. P. B., \& Freitas, S. N. (2016). Manual de Identificação de Altas Habilidades/Superdotação. Guarapuava: Apprehendere.

Piske, F. H. R. (2018). Altas habilidades/superdotação (AH/SD) e criatividade na escola: o olhar de Vygotsky e de Steiner. Tese (Doutorado), Universidade Federal do Paraná, Curitiba, Paraná.

Piske, F. H. R., \& Stoltz, T. (2018). Afetividade e Criatividade na Educação de Superdotados: Uma Proposta A Partir da Ludicidade. In: VIRGOLIM, A. (Org.) Altas Habilidades/Superdotação: Processos Criativos, Afetivos e Desenvolvimento de Potenciais (pp. 201-2012). Curitiba: Juruá.

Prado, A. L., Laudares, E. M. A., Viegas, P. P. C., \& Gourlart, I. C. V. (2017, ago.). Narrativas Digitais: Conceitos e Contextos de Letramento. Revista Ibero-Americana de Estudos em Educação (v. 12, n. esp. 2, pp.1156-1176). Recuperado 15 março, 2020, de http://dx.doi.org/10.21723/riaee .v12.n.esp.2.10286.

Queiroz, R. L., \& Sampaio, F. F. (2016). DuinoBlocks for Kids: Um Ambiente de Programação em Blocos para o Ensino de Conceitos Básicos de Programação a Crianças do Ensino Fundamental I Por meio da Robótica Educacional. Anais XXXVI Congresso da Sociedade Brasileira de Computação (pp. 20862095). Recuperado 29 novembro, 2020, de http://ebooks.pucrs.br/edipucrs/anais/csbc/assets /2016/wei/10.pdf.

Renzulli, J. (2014, set./dez.). Modelo de Enriquecimento para Toda a Escola: Um Plano Abrangente para o Desenvolvimento de Talentos e Superdotação. Trad.: PÉREZ, S.G.P.B. Título original "The Schoolwide Enrichment Model: A Comprehensive Plan for the Development of Talents and Giftedness". Revista Educação Especial (v. 27, n. 50, pp. 539- 562).

Renzulli, J. (2018). Reexaminando o Papel da Educação para Superdotados e o Desenvolvimento de Talentos para o Século XXI: Uma Abordagem Teórica em Quatro Partes. In: VIRGOLIM, A. (Org.). Altas Habilidades/Superdotação: Processos Criativos, Afetivos e Desenvolvimento de Potenciais (pp. 19-41). Curitiba: Juruá.

Renzulli, J. J. (1988). The Three-Ring Conception of Giftedness: A Developmental Model for Creative Productivity. In: Stemberg, R. \& Davidson, J. Conceptions of Giftedness. Cambridge (EUA): University of Cambridge.

Sabatella, M. L. P. (2012). Expandir Horizontes para Compreender Alunos Superdotados. In: MOREIRA, L. C. \& STOLTZ, T. (Org.). Altas Habilidades/Superdotação, Talento, Dotação e Educação (pp. 113-128). Curitiba: Juruá. 
Santos, C. L. (2019). Altas Habilidades/Superdotação na Rede Municipal de Foz do Iguaç/PR: Uma Proposta Educacional com Tecnologias Digitais. Dissertação Mestrado em Ensino), Universidade Estadual do Oeste do Paraná, Foz do Iguaçu, Paraná.

Silva, J. A. L., Oliveira, F. C. S., Martins, D. J. S., \& Silva, W. N. A. S. (2018). Storytelling e Robótica Educacional: a Construção de Carros Robôs com Arduino e Materiais Recicláveis. Anais do XXIX Simpósio Brasileiro de Informática na Educação. Recuperado 10 dezembro, 2020, de http://www.brie.org/pub/index.php/sbie/article/view/8157/5845.

Silva, J. C. M. (2013). O Uso do Software de Autoria Jclic como Ferramenta Pedagógica no Processo de EnsinoAprendizagem de Conteúdos da Matemática nas Séries Finais do Ensino Fundamental Por Meio da Construção de Jogos Educativos. Dissertação (Mestrado em Ciências e Matemática), Universidade Federal do Ceará, Fortaleza, Brasil.

Silva, T. R., Medeiros, T. J., Medeiros, H., Lopes, R., \& Aranha, E. (2015) Ensino-Aprendizagem de Programação: uma Revisão Sistemática da Literatura. Revista Brasileira de Informática na Educação (v. 23, n. 1, pp. 183-196).

Smole, K. C. S. (1999). Múltiplas Inteligências na Prática Escolar. Brasília: Ministério da Educação. Secretaria de Educação a Distância.

Vieira, N. J. W. (2005). Inteligências Múltiplas e Altas Habilidades: uma proposta integradora para a identificação da superdotação. Revista Linhas (v. 6, n. 2). Recuperado 12 dezembro, 2020, de http://revistas.udesc.br/index.php/linhas/article/view/1270.

Wing, J. M. (2006, mar.). Computational Thinking. Communications of the $A C M$ (v. 49, n. 3, pp. 33-35). Recuperado 12 dezembro, 2020, de https://www.cs.cmu.edu/ 15110-s13/Wing06-ct.pdf.

Zilli, S. R. (2004). A Robótica Educacional no Ensino Fundamental: perspectivas e práticas. Dissertação (Mestrado em Engenharia de Produção), Universidade Federal de Santa Catarina, Florianópolis, Santa Catarina, Brasil. 


\section{Sobre os Autores}

\section{CLEONICE DA LUZ DOS SANTOS}

(iD) ORCID: https://orcid.org/0000-0003-2123-4028

Professora na rede municipal de Foz do Iguaçu/PR. Mestra em Ensino pela Universidade Estadual do Oeste do Paraná (Unioeste). Especialista em Educação Especial pelo Centro Internacional de Pesquisa e Extensão Universitária, especialista em Psicopedagogia Escolar pela Faculdade Espírita e Especialista em Didática e Metodologia de Ensino pela Universidade Norte do Paraná. Graduada em Letras e Literatura Brasileira pela Unioeste. É membra do Grupo de Pesquisa em Tecnologia, Inovação e Ensino (GTIE) da Unioeste.

E-mail: luzzcleonice@gmail.com.

\section{CLODIS BOSCARIOLI}

(iD) ORCID: https://orcid.org/0000-0002-7110-2026

Professor associado na Universidade Estadual do Oeste do Paraná (Unioeste). Docente permanente e orientador no Programa de Pós-Graduação em Ciência da Computação (PPGCOMP) - nível de mestrado e no Programa de Pós-Graduação em Educação em Ciências e Educação Matemática (PPGECEM) nível de mestrado e doutorado, ambos no campus de Cascavel e docente colaborador no Programa de Pós-Graduação em Ensino (PPGEN) - nível de mestrado no campus de Foz do Iguaçu/PR. Doutor em Engenharia Elétrica pela Universidade de São Paulo, Mestre em Informática pela Universidade Federal do Paraná e Bacharel em Informática pela Universidade Estadual de Ponta Grossa. É líder do Grupo de Pesquisa em Tecnologia, Inovação e Ensino (GTIE) da Unioeste.

E-mail: clodis.boscarioli@unioeste.br.

Enviado: 31 jan. 2021.

Aprovado: 4 mar. 2021. 